\title{
Impact of Environmental Conditions on Sub-Surface Storage Tanks (Part I)
}

\author{
OWATE, I O; EZI, C W I; AVWIRI, G
}

\author{
Department Of Physics, Environmental Physics Group, University Of Port Harcourt, Port Harcourt. Nigeria.
}

\begin{abstract}
The present investigation concentrates on the effects of environmental changes upon subsurface storage tanks that are frequently used in the Niger Delta region and other parts of Nigeria for Petroleum Products. The research is part one of a long-term study that aims at the determination of corrosion rates of the under ground tanks within the Port Harcourt Municipality. Cast iron made storage tanks with gasoline fluid were buried under the soil at a depth of $4 \mathrm{~m}$ under various environment conditions. The simulated conditions include natural rain fail, temperature and acidic, alkaline and neutral soils. A control condition of neutral sea sand as base and filling materials were also investigated. After various exposure periods, the densities of the storage tanks, composition of soil, soil $\mathrm{pH}$, corrosion rates and soil resistivities were determined. The experiments were repeated after every six months. Within the last three years, it has been observed that the corrosion rates of the tanks covered with cellophane materials were relatively less than those tanks that were buried directly with in the soil except that of the control experiment. In addition the corrosion rates of tanks buried within the acidic environment were more than those buried within the alkaline and neutral soil conditions. Also, it was interestingly observed that the corrosion rates were generally and initially very rapid during the first year of the work, but with time it decreased. Equally the water content of the soil was low. The soil resistivity increased relatively to the control sample site. @ JASEM
\end{abstract}

The use of metallic tanks and pipes as a means of storage and transportation of fluid (petroleum products) is on the increase even with the high technology development. Consequently, the excellent studies on organic inhibitors in paints performed by Braig, (1989); Sastri, (1998) and Scantleburg, (2000) only served as suggestions for corrosion control measures. Several techniques for corrosion control and protection have been developed. Sol-Gel coating and cathodic electrode methods (Jeffery and George, 1990; Alexander, 1998, Alexand and Duc, 1998, 1999 and Alexander and Payan 1998,) are some of the methods that are available as a means of reducing the effects of the environment upon the damage caused on metallic materials. Organic coatings for metals or steel materials have over the years proved effective in reducing corrosion in many environments. This has been achieved through the process of insulating the metal surface from corrosive media. However Researchers (Tsuru et al, 2000) have discovered that when the coating layer is damaged by either mechanical scratches or delimination, corrosion process will be initiated under the film and this gradually proceeds with covered red-rust deposits. In addition it has been stated that corrosion rate under such films is not usually so fast (Braig, 1989, Harvey, 2000 ) as to cause any significant damage. However, the appearance of rusted metal work is not very much acceptable in usual industrial practice. Similarly, cathodic protections for steel products are widely employed in oil and gas exploration, exploitation and transportation within seawater, fresh water, and soils are normally specially manufactured on demand. In contrast, cathodic protection has not been successfully applied within air and on coating film surfaces (Tsuru et.al, 2000). This is because current path for the protection current is not available for this environment. Consequently, the ability of various pigment extracts to reduce galvanic current between Zinc and steel at a cut edge corrosion was evaluated by Heward et al (1996) using a model cell consisting of a "Sandwich" of steel sheet, plastic film and Zinc foil with the galvanic current measured by the electrode impendence method. As a follow-up of the above idea, $Z$ in et al (2000) studied the effectiveness of chromate-free pigments in coil-coated galvanic steel and found that it had significant synergetic anticorrosion effect on the system. For sub-surface facilities (Underground tanks and pipes) one of the greatest problems is the influence of soil composition, organism and load on the coatings. Ole and Unni (2000) Hare (1994) and Funke (1983) investigated the barrier and environmental relationship between corrosion rates and the pigment coatings. However, it was observed that the most important properties of any protective coating include adhesion to the substrate and the anticorrosive protection characteristics. Rodrigue et al (2000) argued that anticorrosive protection should be achieved both as a barrier to aggressive species within the soil by applying a suitable pigment like chromatephosphate system. This idea was strongly supported by other workers (Di Maggio, 1997 and Van, 1993). The application of coated-steel pipes and metal-storage tanks in transportation and distribution of petroleum products and gas within and outside the Niger Delta region has generated conflicts, oil spillages and above all caused greal damage to the ecosystem in particular and the enviromment in

*Corresponding author 
general. The present study aims at identifying the effects of the activities of dynamics of soil environment on sub-surface facilities such as buried storage tanks and pipes. This implies that the rate of corrosion of the system shall be related to the environmental index. The second part of the work shall applied the index obtained is predicting the typical life span of such metal systems.

\section{MATERIALS AND METHODS}

A pilot storage Tank fabricated from mild steel was designed and constructed as presented in Fig 1 . Seven of such Tanks were fabricated and coated with corrosion resistant pigment red lead $\left(\mathrm{pb}_{3} 0_{4}\right)$ which types of pigments are used using standard method (National Bureau of standard 66C and $\triangle$ STM STD $741 \mathrm{X}$ ). The lanks were then allowed to dry in an open atmosphere lor seven days. Seven different sites were chosen and their soil samples collected and analyzed. (Table 3) What soil parameters were analyzed and give the proceeding and their references. Each site was prepared and labeled $A, B$, $C, D, E, F$, and $G$. The environmental conditions of each site are shown in Table 1. The tanks were equally identified with their soil site designations. That is Tank G (the control site) was identified with $\mathrm{G}$, which is equally the soil site identification. All the specimens were buried within their sites under different environmental conditions as previously stated. The soil temperature and rainfall were regularly monitored.

After a period of about six months, the specimens were removed, properly cleaned, washed, dried and a re-weighed. Prior to this period the initial weights of the tanks were noted. Thus by applying the weight- loss techniques and the equation (Fontana, 1986 and Craig 1989)

$$
\text { mpy (mills per year) }=\frac{534 W}{D A T}
$$

The corrosion rate was estimated; Where $W=$ Weight loss (mg) $D=$ Density of sample $\left(\mathrm{g} / \mathrm{cm}^{3}\right)$ $A=$ Area of specimen exposed to corrosion $\left(\mathrm{cm}^{2}\right)$ $\mathrm{T}=$ period of exposure (hours)

Consequently, the infection of the sub-surface soil with $\mathrm{H}_{2} \mathrm{SO}_{4}$ and $\mathrm{NaOH}$ and prevailing conditions such as temperature of the soil and its moisture content were carcfully controlled. The soil samples were later collected after ten days of infection and analyzed. Thereafter, the soil samples were analyzed each time the tanks were removed from the soil for testing. Table 3 indicates the initial chemical composition of the soil before and after 419 days. Also, the method applied by Grosta (1985) was used in the determination of soil resisitivity for the various sites. Thus, the soil resistivity, density of tanks, chemical composition and moisture content of the soil samples at each, sites were determined before and after each period of 92,255 , and 419 days. The chemical composition of each soil samples from the different sites was obtained by atomic absorption emission spectrophotometer (AAES) after digesting the specimens using suitable solvent.

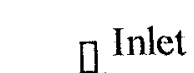

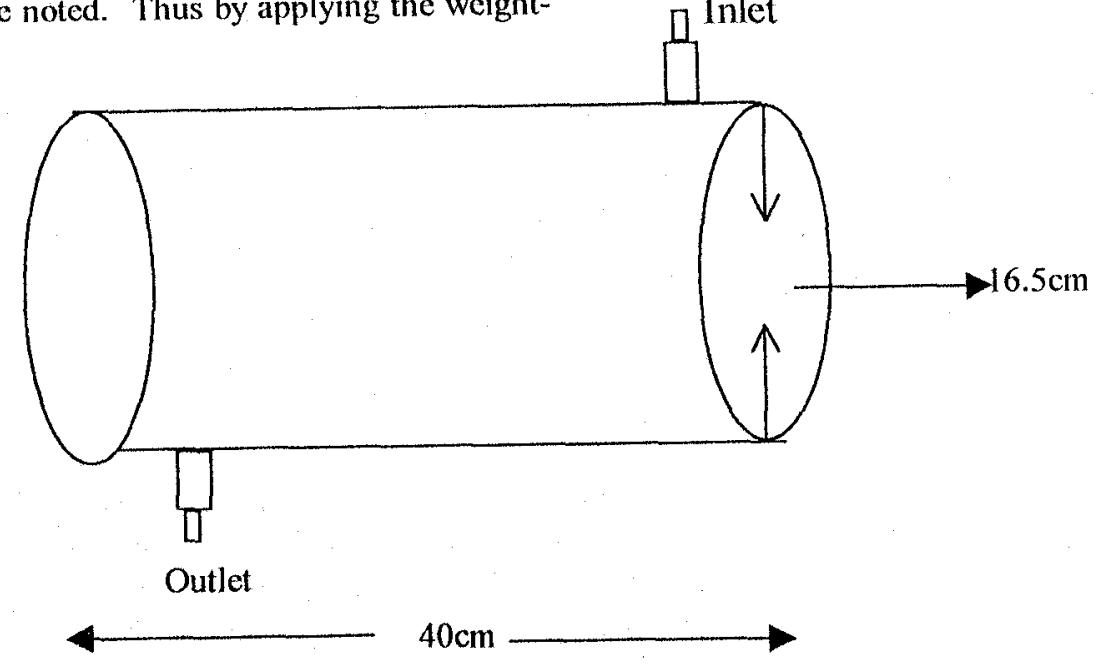

Fig 1. A typical sketch of a storage Tank 


\section{RESULTS AND DISCUSSION}

The measured average densities of the tank materials were initially $88.26 \mathrm{~g} / \mathrm{cm}^{3}$ and it later reduced to about $849 / \mathrm{cm}^{3}$ after exposure as observed in Table 2 . The general reduction in density could be due to materials degradation when exposed to sub-surface soil conditions. Although density reduction with increasingly exposure time were marginal for; the samples, each specimen that was measured had a fairly constant density after each required period of exposure. Also, it is worth mentioning that the control experiment (specimen G) maintain a fairly constant density indicating that the degradation of the material under such controlled conditions was not severe and did not affect the density. This is because the conditions were carefully controlled. The average moisture content of soil was equally determined. It was observed that there were no significant changes in the composition of principal metals. Such metals which include $\mathrm{Al}, \mathrm{Fe}, \mathrm{Ca}$ and Mg. Also $\mathrm{SiO}_{2}$ content was fairly constant through out the period of study. The acidity of locations $A, B$, $C$, and $D$ was reduced whereas the alkalinity of locations $\mathrm{E}, \mathrm{F}$, and $\mathrm{G}$ increased. This means that the climate condition of the soil. However, it will be observed from Table 3 that the control site (location G) was consistently maintaining its composition.

TABLE 1: The storage tanks, their masses and the nature of the various environments

\begin{tabular}{|l|l|l|}
\hline Specimen & Weight (kg) & Nature of various onvironments \\
\hline Tanks A & $8.13 \mathrm{~kg}$ & Buried directly in a Neutral Soil \\
\hline Tank B & $8.10 \mathrm{~kg}$ & Covered with a cellophane material and buried in a Neutral Soil. \\
\hline Tank C & $8.11 \mathrm{~kg}$ & Buried directly in a soil infested with $\mathrm{H} 2 \mathrm{SO}_{4}$ \\
\hline Tank D & $8.13 \mathrm{~kg}$ & Covered with cellophane material and buried in a soil infested with $\mathrm{H}_{2} \mathrm{SO}_{4}$ \\
\hline Tank E & $11.00 \mathrm{~kg}$ & Buried directly in a soil infested with $\mathrm{NaOH}$ \\
\hline Tanks F & $9.00 \mathrm{~kg}$ & Covered with cellophane material and buried in a soil infested with $\mathrm{NaOH}$ \\
\hline Tank $\mathrm{G}$ & $8.03 \mathrm{~kg}$ & Covered with a cellophane material and placed in amass concrete plat form. \\
\hline
\end{tabular}

TABLE 2 Densities of the storage tanks.

\begin{tabular}{|c|c|c|c|c|c|}
\hline & \multirow[t]{2}{*}{ Soil samples } & \multicolumn{4}{|c|}{ Dens)ty $\left(\mathrm{g} / \mathrm{cm}^{3}\right)$} \\
\hline & & After 0 Day & After 92 Days & After 255 days & After 419 days \\
\hline $\mathrm{A}$ & Buried in Neutral soil & 81.24 & 77.84 & 76.14 & 76.14 \\
\hline $\bar{B}$ & $\begin{array}{l}\text { Covered with cellophane and } \\
\text { buried in neutral soil }\end{array}$ & 80.94 & 77.84 & 76.34 & 76.14 \\
\hline $\mathrm{C}$ & Soil infested $\mathrm{H}_{2} \mathrm{~S} 4$ & 81.04 & 77.54 & 76.34 & 76.14 \\
\hline $\mathrm{D}$ & $\begin{array}{l}\text { Covered with cellophane and } \\
\text { infested with } \mathrm{H}_{2} \mathrm{SO}_{4}\end{array}$ & 81.24 & 77.44 & 76.94 & 76.14 \\
\hline $\mathrm{E}$ & $\begin{array}{l}\text { Covered with cellophane and } \\
\text { infested with } \mathrm{NaOH}\end{array}$ & 109.91 & 102.12 & 102.02 & 101.92 \\
\hline $\mathrm{F}$ & Buried in soil infested with $\mathrm{NaOH}$ & 99.93 & 97.44 & 96.54 & 75.94 \\
\hline$G$ & $\begin{array}{l}\text { Covered with cellophane a.d } \\
\text { placed in a mass concrete platform }\end{array}$ & 83.53 & 83.33 & 82.93 & 82.53 \\
\hline & Average Densities & 88.26 & 84.79 & 83.89 & 83.71 \\
\hline
\end{tabular}

What was clear from both Tables 3 and 4 was that the different locations had slight differences in acidity condition of the soil. This was basically observed in this study because since increased acidity or alkalinity was one of the conditions for increasing corrosion depending on other prevailing conditions. Besides, moisture content, high concentration of ions of iron and other materials are known agents of corrosion. Thus the reactions of soil with metals are numerical expressions of their relative acidity or alkalinity. The samples (Tanks) were removed from the soil location identified, washed, dried, photographed and individually weighed. The results obtained over the period are shown in Tables 2 and 4 . Sequentially, sample $A$ represent the Tank buried under normal natural soil condition, sample $B$ is for the specimen that was carefully covered with cellophane material and buried under similar condition as sample A. For sample $\mathrm{C}$ the soil environment was infested with acid $\mathrm{H}_{2} \mathrm{SO}_{4}$ while soil environment for sample $\mathrm{E}$ was infested with a base $\mathrm{NaOH}$. Similarly, samples D and F were covered with cellophane materials. The control experiment was for location $G$ where the site was properly prepared as indicated under materials and method. Cellophane material when used to properly cover metals (iron) are known to retard corrosion, rate as shown in Table 4.

Thus, it was generally observed that there was a gradual decrease in weight with time which gave rise 
to increasing weight losses. However, these losses were relatively more in samples $A, C$, and $E$ and low in samples B,D and $F$ but lower in sample $G$. The different is because samples $A, C$ and $E$ were not covered with cellophane and thereby well-expos\%d to easy corrosion attack than samples B, D and F that were carefully covered with cellophanc materials. In addition sample $G$ was exposed to controlled conditions that inhibited corrosion and no significant loss in weight was noted when compared to other samples. The above weight losses were applied in computing the corrosion rates for materials at various locations (Table4). The corrosions rates and soil resistivities for the samples at the different location and conditions a presented in Table 4 indicates reduction with time. Also, the nature of the corrosion by visual examination is shown in Fig 2 and 3 . Impressively, the weight losses were reflected in the calculated corrosion rates. It was observed that specimen covered with cellophane materially generally had lower corrosion rates than specimens that were left open to attack by the environment. Similarly, there was a general decrease in corrosion rates with time. A comparative analysis between corrosion rates and soil resistivities (Table 4) indicates the following.

(i) Increasing soil resistivity suggests a reduction in corrosion ratc.

(ii) There is a simple corrolation between corrosion rates and soil resistivity.

The above observation could be deduced from the fact that the corrosion was of an electrolytic conduction mechanism. Thus, if the environment is more conductive, it exposes the material to high degree of electrolytic processes thereby leading to higher rate of corrosion. This is why in construction of pipeline; the proposed route should be surveyed to determine the probable corrosive regions where protective measures needs enhancement. In doing this type of survey, soil resistivity measurements are usually encouraged.

TARLE 3 Chemical composition of the soil samples (at zero days)

\begin{tabular}{|l|l|l|l|l|l|l|l|}
\hline \multirow{2}{*}{$\begin{array}{l}\text { No of } \\
\text { Days. }\end{array}$} & \multirow{2}{*}{$\begin{array}{l}\text { Sample } \\
\text { site }\end{array}$} & \multirow{2}{*}{$\mathrm{pH}-1$} & \multicolumn{2}{|l|}{ Weight per cent (\%) } \\
\cline { 4 - 8 } & & & $\mathrm{SiO}_{2}$ & $\mathrm{Al}$ & $\mathrm{Fe}$ & $\mathrm{Ca}$ & $\mathrm{Mg}$ \\
\hline 0 & $\mathrm{~A}$ & 6.09 & 99.79 & 0.064 & 0.004 & 0.0003 & 0.0005 \\
419 & & 6.65 & 99.79 & 0.091 & .005 & .0001 & 0.0006 \\
\hline 0 & $\mathrm{~B}$ & 6.03 & 99.28 & 0.36 & 0.005 & 0.00 & 0.005 \\
419 & & 6.63 & 99.86 & 0.09 & 0.005 & 0.0001 & 0.00005 \\
\hline 0 & $\mathrm{C}$ & 5.50 & 99.54 & 0.040 & 0.005 & 0.0016 & 0.0003 \\
419 & & 5.86 & 99.73 & 0.089 & 0.008 & 0.0012 & 0.00002 \\
\hline 0 & $\mathrm{D}$ & 5.36 & 99.81 & 0.030 & 0.031 & 0.0053 & 0.0004 \\
419 & & 5.86 & 99.73 & 0.089 & 0.008 & 0.0012 & 0.00002 \\
\hline 0 & $\mathrm{E}$ & 8.18 & 99.68 & 0.176 & 0.014 & 6.0052 & 0.00003 \\
419 & & 8.58 & 99.66 & 0.102 & 0.029 & 0.00422 & 0.00004 \\
\hline 0 & $\mathrm{~F}$ & 8.15 & 99.89 & 0.078 & 0.0086 & 0.001 & 0.00007 \\
419 & & 8.55 & 99.48 & 0.100 & .015 & 0.039 & 0.0005 \\
\hline 0 & $\mathrm{G}$ & 6.84 & 99.86 & 0.09 & 0.006 & 0.00006 & 0.00008 \\
419 & & 6.86 & 99.89 & 0.09 & 0.006 & 0.00006 & 0.00008 \\
\hline
\end{tabular}

TABLE 4 Corrosion rates (mpy) and Soil resistivity (ohms-cm)

\begin{tabular}{|l|l|l|l|l|l|l|}
\hline \multirow{2}{*}{$\begin{array}{l}\text { Nature of } \\
\text { site }\end{array}$} & \multicolumn{3}{|l|}{ Corrosion rates (mpy) } & \multicolumn{2}{l|}{ Soil Resisitivity $(\Omega \mathrm{cm})$} \\
\cline { 2 - 7 } & 92 days & 255 days & 419 days & 92 days & 255 days & 419 days \\
\hline A & 0.40 & 0.26 & 0.22 & $9097 \times 10^{4}$ & $15.4 \times 10^{4}$ & $18.1 \times 10^{4}$ \\
\hline B & 0.37 & 0.24 & 0.21 & $10.8 \times 10^{4}$ & $16.67 \times 10^{4}$ & $19.00 \times 10^{4}$ \\
\hline C & 1.13 & 0.42 & 0.26 & $3.51 \times 10^{4}$ & $9.49 \times 10^{4}$ & $15.4 \times 10^{4}$ \\
\hline$D$ & 1.15 & 0.27 & 0.18 & $3.45 \times 10^{4+}$ & $14.9 \times 10^{4}$ & $22.2 \times 10^{4}$ \\
\hline E & 0.69 & 0.25 & 0.15 & $5.77 \times 10^{4+}$ & $15.9 \times 10^{4}$ & $26.6 \times 10^{4}$ \\
\hline F & 1.34 & 0.56 & 0.38 & $2.96 \times 10^{4}$ & $7.11 \times 104^{4}$ & $10.5 \times 104$ \\
\hline G & 0.023 & 0.04 & 0.04 & $2.63 \times 10^{-2}$ & $1.63 \times 10^{-4}$ & $1.02 \times 10^{-4}$ \\
\hline
\end{tabular}


CONCLUSIONS: The rate of corrosion of metals (sub-surfaced storage ranks) depends solely on the environment in which they are laid. The soil constituent (environment) on which the various

storage tanks were laid equally has their different impact on these tanks. This work has showed that corrosion rate of sub-surface storage tanks depends upon the soil factors which stimulates corrosion.

From the experimental results, tanks $F$ and $C$ had the highest corrosion rate followed by tanks $A$ and $B$, before tank $D$ and $E$. The soil resistivity showed that the lower, the restistivity of the soil, the higher the effect of corrosivity of the soil on the metal. This stimulates the rate of corrosion of the tanks. Later exposures show that the corrosion rates has decreased due to the accumulation of more protective corrosion products on the metal surface

\section{REFERENCES}

Alexander, M.R and Duc, T.M (1998); J. Mat. Sc chem.. 8, 937-40

Alexander, M.R and Mc Alpine (2000); Plasma polyerized coating; J. of corrosion Science and Engineer 2(32), $321-323$

Alexander, M.R. and Duc. T.M (1999), Polymer 40, 5479.

Alexander, M.R. and Payne, S (1998), Surface and Interface Analysis, 26, 961-969.

Braig, A (1989); Advances in corrosion protection, Kendig publishers, Pennington N.J.

Craig, B.D (1989); Handbook of corrosion data., ASMT, New York, 62-70.

Di- Maggio, R; Rossi, S and Scardi (1998) Surface coating of metals; surface and coating Technical $89,292-298$

Fontana, M.G. (1986), Corrosion Engineering $3^{\text {rd }}$ edition McGraw-Hill, 262-272.

Fontana, M.M and Greene, N.D. (1978), Corrosion Engineering $2^{\text {nd }}$ Edition, McGraw-Hill, New York, 142-147
Funke, W. (1983), Towards Environmentally acceptable corrosion protection by organic coating problems and realization; Journal of coatings Technology 55; 131-138

Hare, C.H. (1994), Protective-coating fundamentals; Publish, Pittsburgh. P31-30.

Harvey, P.H. (2000), Corrosion control- galvanic corrosion and stainless steel; J. Marine Technology 210-216

Howard, R.L and Lyon, S.B (1996); Organic inhibitors in mild steel, Proceeding $13^{\text {th }} \mathrm{ICC}$ Melbourne Australia P 022.

Jeffrey, C and George, W. Schere (199); Sol-Gel Sciences, Academic Press London

Ole Knudsen and Unni steinsmo (2000), Effects of Barrier pigments on cathodic disbanding; Journal of Corrosion Science and Engineer. 2 (13), 13138.

Rodriguez, F.J, and Bonora, P. (2000), Evaluation of Amorphous Zirconium films as adhesion promoters for organic coating; Journal of corrosion sciences and Engineering 2, 10-16

Romanoff, M, (1962) corrosion steel piling in soils; J. Research National Bureau of standards $66 \mathrm{C}-8$, 10-17

Sabine, S (2000), Passivation aspects. J of corrosion Sc. and Engr. 12,20-26.

Sastri. V. S. (1998); Corrosion inhibitors, Wiley Chichester, 46-52.

Scanteburg and Xiu, D (2000), Sol-gel derived antcorrosion pigment. J. of corrosion Sc. and Engr. 2, 22-30.

Tsuru, T and Nishikata (2000); Organic coatings for protection in atmospheric condition; J. of corrosion Sci. and Engr. 2, 264-268

Van, W.J. Edwards, R.A. and Zappia, J. (1995). The strength of chromate pigment; J. Adiesion Sci Technol. 7 (8), 897-917.

Zin, I.M. Lyon, S.B, and Badger, S.J (2000), Inhibiting Pigments in Coil-coated Galvanized steel; $J$ of corrosion science and Engineer. 3-6. 